\title{
Inescapable shock and food-competition dominance in rats
}

\author{
PETER M. RAPAPORT and STEVEN F. MAIER \\ University of Colorado, Boulder, Colorado 80309
}

\begin{abstract}
Inescapable electric shock disrupts escape-avoidance learning in another apparatus. This study demonstrates a deficit in a nonlearning task in which no aversive stimulus occurs. In Experiment 1, inescapable shock lowered rats' dominance in a food-competition situation relative to restrained controls. In Experiment 2, inescapable shock lowered rats dominance in the same food-competition situation relative to a group that received the equivalent amount of escapable shock, demonstrating that the inescapability of the shock caused at least part of the decrement observed in Experiment 1. Experiment 3 does not find that inescapable shock caused a significant difference in food consumed or running time when the rats were tested alone, showing it unlikely that the dominance effects were caused by decreased hunger or reduced running following inescapable shock.
\end{abstract}

Variations in the degree to which organisms can control electric shocks to which they are exposed has both behavioral and physiological consequences (see Maier \& Seligman, 1976 for a review), although the behaviors that have been shown to be influenced by exposure to inescapable shock all involve learning, aversive stimuli, or both. The range of behaviors influenced by prior exposure to inescapable shock remains unknown. There should be boundary conditions so that not all behaviors would be affected, but these conditions have not been explored. The purpose of the present series of studies was to discover whether exposure to inescapable shock can produce deficits in psychological processes other than learning in situations in which aversive stimuli do not occur. This seemed a reasonable first step in attempting to delineate the behavioral boundary conditions of inescapable shock effects.

We chose to study whether exposure to inescapable shock would reduce the organism's position in a dominance hierarchy established in a food-competition situation. This seemed a reasonable choice because no obvious aversive stimulus such as electric shock is involved and the behavior does not appear to be learned during testing. It could be argued that the encounter between two rats during dominance testing is aversive, but it should be noted that the rats do not fight. Thus, at a minimum, physical pain is not involved. The behavior involved does not appear to be learned during testing, because the hierarchy typically appears on the very first test and remains stable if tested again (Stewart \& Palfai, 1967). Because ines-

This research was supported by Grant MH 26827 to Steven F. Maier from the National Institute of Mental Health. Requests for reprints should be sent to Steven F. Maier, Department of Psychology, University of Colorado, Boulder, Colorado 80309. capable shock does depress the level of subsequent shock-elicited aggression (Maier, Anderson, \& Lieberman, 1972), it might be expected that other forms of agonistic behavior, such as food-competition dominance, might also be reduced. In addition, Seligman (1975) has argued that exposure to uncontrollable aversive events produces a general emotional depression. Such an effect might lead one to expect a reduction in dominance.

It should be noted that there is some question concerning whether there exists a unitary dimension of dominance (Crook, 1970; Gartlan, 1968; Van Krevland, 1970), for a unitary interpretation requires a high correlation between food-competition dominance and various other dominance tests. In rats, food competition has been found to correlate with water competition (Baenninger, 1970). Limited access or competition measures and agonistic behavior have been found to correlate by Lindzey, Manosevitz, and Winston (1966) and Ruskin and Corman (1971), but not by Baenninger (1970) or Drews and Wulczyn (1975). Drews and Wulczyn found a high correlation between agonistic behavior and other observational, seminaturalistic measures, such as grooming and mounting. Drews and Dickey (1977) replicated this finding, but also found another cluster of competitive and other measures more typically studied in the laboratory. While each of these clusters was highly correlated, the two clusters showed little cross-cluster correlation. Thus, it is not clear that there is a unitary trait of dominance, but it does appear that the food-competition measure used in this study is not an isolated behavior, but is correlated with other behaviors of interest. For our purposes it is not vital that dominance be a unitary trait, but that it be an instance of a largely unlearned behavior not involving shock motivation. 


\section{EXPERIMENT 1}

Stewart and Palfai (1967) developed a procedure that produces stable dominance hierarchies across successive tests. Experiment 1 utilized their procedure to first establish a hierarchy. Some of the rats were then exposed to inescapable shock and some were only restrained. Dominance was retested in order to discover whether exposure to inescapable shock altered the rats' position in the hierarchy.

\section{Method}

Subjects. The subjects were 16 male albino Holtzman rats, 80-90 days old. The rats were deprived of food for 2 days prior to the start of the experiment. During the experiment, the subjects were allowed to eat for $1 \mathrm{~h}$ a day in their home cage. They were maintained on ad-lib water and were run during the light phase of the 12-h on/12-h off light-dark cycle.

Apparatus. The dominance testing apparatus was a modified $Y$-maze. The two side arms were $37.2 \mathrm{~cm}$ long, $12.3 \mathrm{~cm}$ wide, and $34.0 \mathrm{~cm}$ high. There were guillotine doors placed $8 \mathrm{~cm}$ from the food cup end of the arms. The center arm was $8 \mathrm{~cm}$ long, and had an 8.5 -cm-diam, 3.5-cm-high, round food cup on a $2-\mathrm{cm}$ raised platform that was $10.1 \mathrm{~cm}$ long and $12.3 \mathrm{~cm}$ wide. This area was large enough for only one rat at a time to eat at the food cup.

The rats were shocked in a round Plexiglas restraining tube that was $24 \mathrm{~cm}$ long and $7 \mathrm{~cm}$ in diameter and had a flat tail restraint shaft. Unscrambled shock was delivered by a shock source modeled after a Grason-Stadler Model 700 shock generator via two electrodes $(8 \times 8 \mathrm{~mm})$ taped to the rat's tail and coated with electrode paste.

Procedure. All rats were first trained to run to the food cup following the lifting of the door. Each rat was placed on one side of the maze for $15 \mathrm{sec}$. The door was raised and the rat was allowed to explore the apparatus until a pellet from the food cup was eaten. He was then given 2 additional minutes before being placed in the other side, where the process was repeated. This training was given to each rat on 4 consecutive days. The side on which the rat started was alternated each day.

The rats were given dominance tests on Days 5 and 6 . Each rat was tested once against every other rat. The dominance test is described in detail in Stewart and Palfai (1967). Each test lasted $120 \mathrm{sec}$, with this time being divided between the two rats. Thus, for example, if rat $A$ was in control of the food cup for $67.3 \mathrm{sec}$, rat B was in control for $52.7 \mathrm{sec}$. The rat received credit for all time during which he was closer to the food cup than the other rat. A dominance hierarchy was constructed, based on the number of wins (defined as times over $60 \mathrm{sec}$ ). Ties were broken by total time in control over all tests.

Rats with rankings $1,4,5,8,9,12,13$, and 16 were placed in Group 1. The other rats were placed in Group 2. It was then determined randomly that Group 1 be the restrained (R) group and Group 2 be the preshocked (P) group. On Day 7, the P group was given 80 unsignaled inescapable $5-\mathrm{sec} 1.0-\mathrm{mA}$ shocks on an average of once every minute (a VT 1-min schedule with a range of 5-200 sec) in the restraining tubes. The $R$ group was placed into identical restraining tubes for an equivalent period of time, but received no shocks.

On Day 8 , all members of the $P$ group were tested in the same dominance test against all members of the $R$ group. ${ }^{1}$ The experimenter was not aware of group membership at the time of the dominance tests. On Day 9, all rats were tested against all members of their own group.

\section{Results and Discussion}

Both groups had a mean of 7 out of a possible 14 wins on the first test. The mean time in control of the food cup on both the tests preceding and following the experimental treatment can be seen in Figure 1. On the first test, the mean time in control was $61.4 \mathrm{sec}$ for Group $R$ and $58.8 \mathrm{sec}$ for Group P $(U=24, p>.30)$. On the second test, the mean time in control was $69.8 \mathrm{sec}$ for Group $R$ and $51.7 \mathrm{sec}$ for Group $P(U=0$, $p<.001)$. In addition, the mean number of wins was 9.1 for Group $R$ and 5.1 for Group P $(U=0.5$, $\mathrm{p}<.001)$.

It should be emphasized that both the number of wins and the time in control measures are conservative. What is of importance is the difference between groups, and both measures include intragroup tests taken on the 2nd day of testing. In the case of the total number of wins, the difference between the scores is an accurate measure of group differences, but the total scores of both groups were inflated by intragroup wins. An additional problem with this measure is a possible floor effect. Out of its mean of 5.1 wins, the $P$ group was guaranteed 3.5 wins, since each $P$ rat had seven tests against other $P$ rats. The total time in control does not have this problem, but it underestimates the group differences by almost half, since it must average in guaranteed scores of $60 \mathrm{sec}$ for each intragroup test (which comprise almost half of the tests). When the animals were separated into two groups, relative dominance was controlled on the basis of tests against all

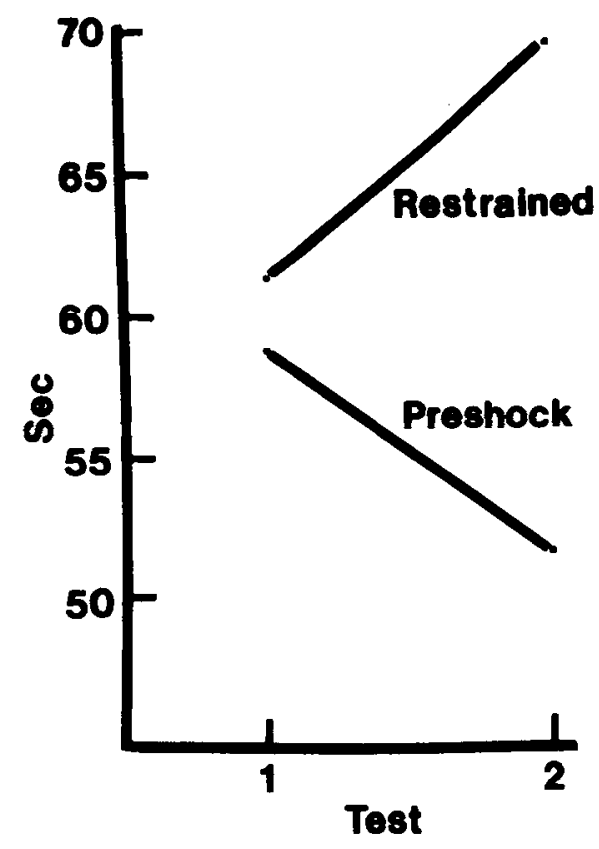

Figure 1. Mean time in control of food. Test 1 refers to dominance tests on Days 5 and 6. Test 2 refers to dominance tests on Days 8 and 9. 
other subjects. In order to make these control procedures meaningful, it was necessary to compare the final test results with the results of the entire initial test. Employing a less conservative measure which utilizes only intergroup tests would result in comparing the test results to only half of the initial tests. Throwing out such a large portion of the initial control test would result in making such controls less meaningful. This was the reason it was necessary to use these conservative measures. Using the less conservative measure of intergroup tests, the mean time in control of the second test was $76.2 \mathrm{sec}$ for Group R and $44.0 \mathrm{sec}$ for Group $P$ $(U=0, p<.001)$. It should be remembered that these tests represent only half the Test 1 matrix to which they are being compared.

Test-retest reliability was estimated by computing the correlation of Test 1 and Test 2 rankings within groups. These scores were $r_{s}=1.00$ for the $R$ group and $r_{s}=.93$ for the $P$ group. This demonstrates that a stable dominance hierarchy was established by our measure before the treatment.

The results of Experiment 1 are clear. Exposure to inescapable shock reduced the rat's position in a food-competition dominance hierarchy. It is possible that this result was produced by exposure to shock per se rather than by the inescapability of the shock. Escapable shock might produce the same effect.

\section{EXPERIMENT 2}

This experiment compared the effects of escapable and inescapable shock in changing the rat's position in the food-competition dominance hierarchy. The rats were first tested for dominance: Some rats were given shock escape training in a small wheel-turn box, while others received inescapable shocks yoked to the shock durations produced by the first group. All rats were again tested for dominance.

\section{Method}

Subjects. The subjects were 16 albino male Holtzman rats, 80-90 days old. Housing conditions were as described in Experiment 1.

Apparatus. Shock-escape training was given in a wheel-turn box. The box was $20 \mathrm{~cm}$ high, $11.5 \mathrm{~cm}$ wide, and $7.3 \mathrm{~cm}$ long at the top and $19 \mathrm{~cm}$ long at the bottom, with a slight inward slope on the back wall. The wheel was $8.8 \mathrm{~cm}$ wide, with a diameter of $7 \mathrm{~cm}$. The bottom of the wheel was $8.5 \mathrm{~cm}$ from the grid floor and the wheel protruded $.5 \mathrm{~cm}$ into the cage through a hole that was $9.6 \mathrm{~cm}$ wide and $7 \mathrm{~cm}$ high. The bottom of this hole was $9.5 \mathrm{~cm}$ from the floor. The rear wall had a 3-cm-high, 2.3-cm-wide hole, from which a flat tail restraint shaft extended, to which the rats were taped. Shock was delivered to the tail as in the restraining tube in Experiment 1. The box was located in a sound-attenuating chamber.

Dominance testing was conducted in the same apparatus as described in Experiment 1.

Procedure. All rats were first tested in the dominancetesting apparatus, as described in Experiment 1. Twenty-four rats were used to insure against the animals' failing to learn the escape task. The rats were then divided into two groups, as in Experiment 1. The escapable (E) group was given 80 trials of escape training. The escape trials occurred on a VT 1-min schedule (range $5-200 \mathrm{sec}$ ). The escape response was one-half of a wheel turn. Shock was pulsated (.5 sec on, $.5 \mathrm{sec}$ off), and lasted $20 \mathrm{sec}$ in the absence of an escape response. Shock intensity started at .6 mA, and was increased to $1.0,1.3,1.6$, and $2.0 \mathrm{~mA}$. Shock was increased after Trials 10,20,30, and 40. If a failure to escape occurred, the next preplanned shock increase was made at that time. The yoked $(Y)$ group received inescapable shock in the same apparatus. Each Y group member was yoked to a member of the $E$ group. Shock began at the same time for both rats and terminated for both whenever the escape subject responded. Shock intensity was increased for both subjects at the same time. Eleven rats were used to obtain eight who learned the escape task to a criterion of nine escapes in the last 10 trials. Only the eight $E$ group rats who learned and their $Y$ group partners were given a dominance retest. The dominance retest was identical to that used in Experiment 1 and occurred $24 \mathrm{~h}$ after the wheel-turn treatment.

\section{Results and Discussion}

Dominance scores were computed to include only the 16 rats used in the experiment. On the initial test, Group E had a mean of 7.25 wins and Group $Y$ had a mean of 7.75 wins $(U=33, p>.50)$. Figure 2 shows the mean time in control of the food cup for both dominance tests. On the first test, Group $E$ had a mean of $60.3 \mathrm{sec}$ in control and Group $Y$ had $59.7 \mathrm{sec}$ in control $(U=30, p>.40)$. After treatment in the wheel. turn box, Group E had control for $64.7 \mathrm{sec}$ and Group $\mathrm{Y}$ for $55.3 \mathrm{sec}(U=6, p<.002)$. The mean number of wins on the second test was 8.25 for Group $E$ and 6.75 for Group $Y(U=13.5, p<.03)$. As in Experiment 1 , it should be emphasized that these measures are conservative. Using the intergroup tests measure, the mean time in control on the second test was $68.8 \mathrm{sec}$ for Group E, and $51.2 \mathrm{sec}$ for Group Y $(\mathrm{U}=3, \mathrm{p}<.001)$. The correlations of the rankings on the two tests within groups were: $I_{s}=.98$ for Group $E$ and $r_{s}=.81$ for Group Y.

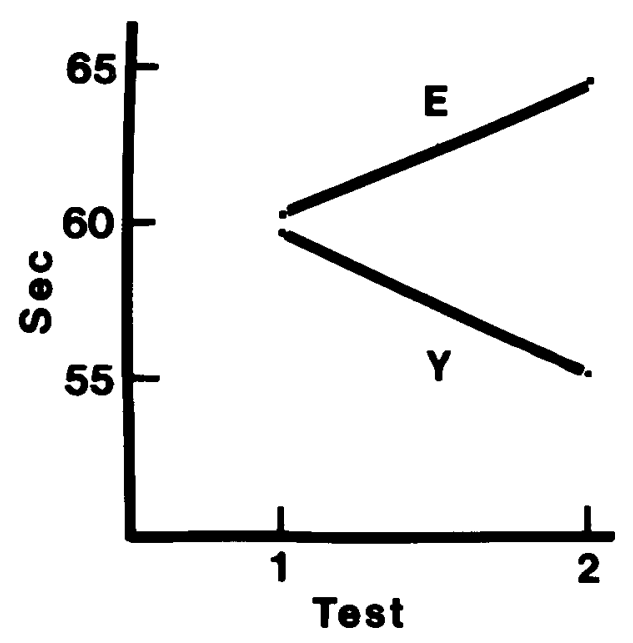

Figure 2. Mean time in control of food. 
Again, these results seem clear. Exposure to inescapable shock reduced the rat's position in the dominance hierarchy relative to rats given inescapable shock. The size of this reduction was quite comparable to that found in Experiment 1, where inescapably shocked rats were compared with rats that had only been restrained. It is not possible to conclude that the entire effect observed in Experiment 1 was caused by the inescapability of shock, as no restrained control group was used in Experiment 2 (the logistics of dominance testing made the use of three groups impossible). At least part of the reduction in dominance is produced by the inescapability of the shock rather than by shock itself.

Although it is clear that exposure to inescapable shock reduces the rat's position in the dominance hierarchy, the mechanism responsible is not apparent. One simple possibility which would render the present results less interesting than otherwise might be the case is that the inescapably shocked rats are simply less hungry. This is plausible because Weiss (1968) has shown that inescapably shocked rats later lose more weight and eat less than do escapably shocked rats, although it should be noted that Weiss used much more intense and prolonged shocks than did the present studies. Another simple possibility is that the inescapably shocked rats run down the alley toward the food cup more slowly and thus begin the trial by not being in control of the cup. This slower running could be caused by norepinephrine depletion (Weiss, Glazer, \& Pohorecky, 1975) or the acquisition of motor responses that compete with running (Glazer \& Weiss, 1976a, 1976b). Experiment 3 was conducted to assess these two possibilities.

\section{EXPERIMENT 3}

This experiment attempted to determine if . rats inescapably shocked with the shock parameters used in Experiments 1 and 2 later run more slowly in the dominance apparatus or are less likely to eat in the dominance-testing apparatus. The rats were first tested for dominance in the dominance-testing apparatus. Some rats were then given escapable shock in the wheel-turn apparatus and some were given inescapable shock. Instead of receiving a subsequent dominance test, all rats were tested alone in the dominance. testing apparatus. The time to run to the food cup and the amount eaten in 2 min were recorded.

\section{Method}

Subjects. The subjects were 16 male Holtzman rats, as in Experiment 2.

Apparatus. The apparatus was the same as in Experiment 2

Procedure. The rats received preliminary training and testing in the dominance apparatus as in Experiment 2. The animals were then separated into Groups $E$ and $Y$ as in Experiment 2. These groups were treated in the wheel-turn apparatus as in Experiment 2. On the following day, both groups were tested individually in the dominance-testing apparatus. Each rat was placed in one leg of the maze; the door was raised and the time to run to the food cup was recorded. The rat was allowed to eat for $2 \mathrm{~min}$ and the amount of food eaten was recorded. This was repeated eight times for each rat.

\section{Results and Discussion}

The mean number of grams of food eaten by the two groups is shown in Figure 3. Group $E$ ate a mean of $1.04 \mathrm{~g}$ and Group $\mathrm{Y}$ a mean of $1.11 \mathrm{~g}(\mathrm{U}=23, \mathrm{p}>.10)$. Figure 4 displays the mean running time to the food cup for both groups. Group E reached the food cup in a mean of $1.55 \mathrm{sec}$ and Group $Y$ required $1.37 \mathrm{sec}$ $(U=24, p>.20)$. While neither of these differences approached significance, it should be noted that the differences are in the opposite direction from that necessary to explain the results of the previous experiments as being caused by reduced eating or running speed.

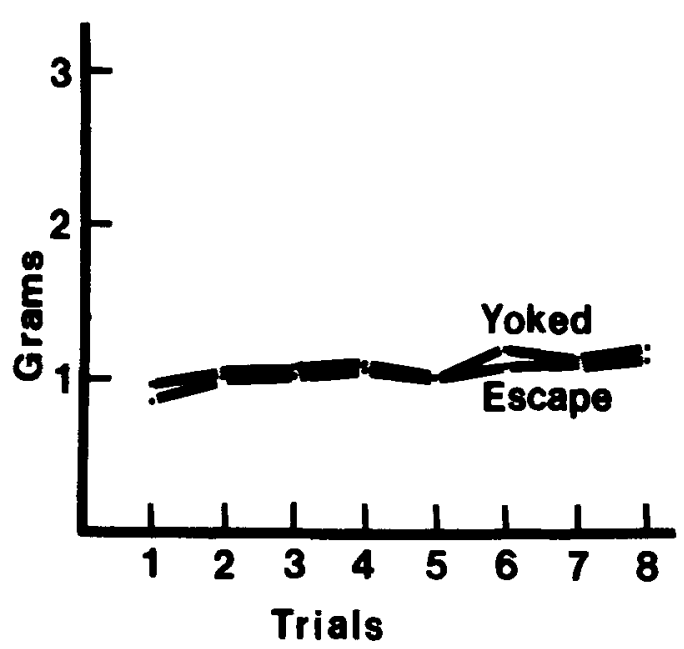

Figure 3. Mean amount of food consumed across eight test trials.

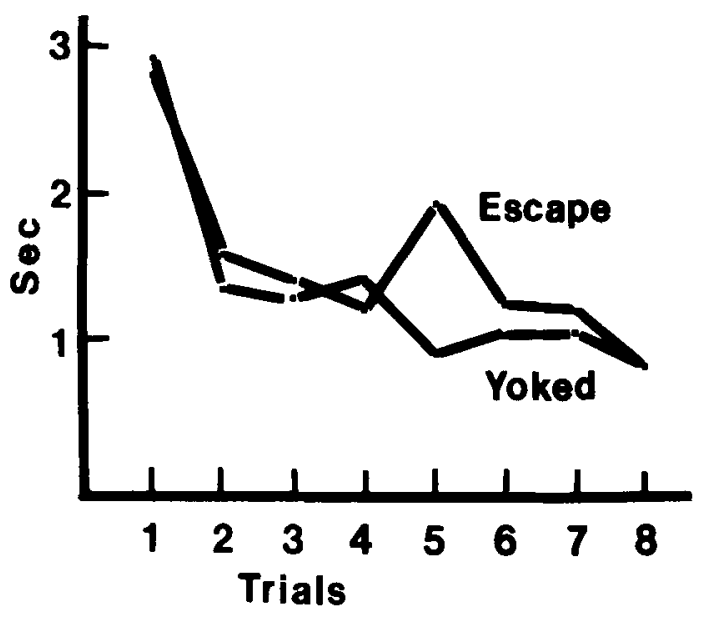

Figure 4. Mean time to reach the food cup across the eight test trials. 


\section{GENERAL DISCUSSION}

The present experiments demonstrate that exposure to inescapable shock does disrupt dominance in a foodcompetition situation (Experiment 1) and that this disruption is at least partly produced by the inescapability of the shock (Experiment 2). It is not likely that this effect is mediated by decreased hunger or slower running to the food cup (Experiment 3).

It has been previously shown that rats exposed to uncontrollable electric shocks (1) later fail to learn to escape shock in a different situation (Maier, Albin, \& Testa, 1973); (2) are slow to learn to escape in a water maze (Altenor, Kay, \& Richter, 1977); (3) are slow to learn to escape from a goalbox in which expected reward is omitted (Rosellini \& Seligman, 1975); (4) show reduced aggressiveness in a shockelicited aggression test (Maier, Anderson, \& Lieberman, 1972); and (5) show physiological symptoms of severe stress (Weiss, 1968). Rats exposed to escapable (controllable) shocks do not show these deficits. Foodcompetition dominance may now be added to this list.

The high correlation found in Experiments 1 and 2 between Test 1 and Test 2 in the groups which were given inescapable shock was a surprising result. It suggests that inescapable shock did not lead to a complete disorganization of dominance behavior, but to a nearly uniform lowering of some activity or set of activities that are necessary in this dominance task. If inescapable shock had led to a complete disorganization of dominance behavior, there should have been little or no correlation between Test 1 and Test 2 performance within the groups which received inescapable shock. There is another possible cause for part of these high correlations. Almost half of the tests included in these correlations were on the 2nd day following shock. Although Glazer and Weiss (1976a) and Rosselini and Seligman (1975) have found no diminution of the helplessness effect in rats over time, we have consistently found little or no evidence of a learned helplessness effect $48 \mathrm{~h}$ after the inescapable shock. It is possible that there was some general disorganization, but that this effect dissipated. Until the question of whether a time course exists for learned helplessness in rats is resolved, it is difficult to evaluate this possibility.

It is not clear how to explain the fact that inescapable shock disrupts food-competition dominance. A variety of hypotheses have been advanced to account for the effects of inescapable shock on escape/avoidance acquisition (see Maier \& Seligman, 1976, for a review), but none of these seem well suited as an explanation of the present findings. Weiss, Glazer, and Pohorecky (1975) have argued that intense and prolonged inescapable shocks deplete norepinephrine. The depletion of norepinephrine is said to make movement difficult. Experiment 3 found no support for reduced movement.
In addition, the inescapable shocks used here would not meet their definition of intense and prolonged.

Anisman and Waller (1973), Bracewell and Black (1974), and Glazer and Weiss (1976a, 1976b) have all argued that a motor response of inactivity is acquired during exposure to inescapable shock and that this reduced movement response transfers to the escape/ avoidance test situation. These positions differ only with regard to the mechanism by which the lack of movement in response to shock is acquired. These views all imply or state that the presence of electric shock mediates the transfer of inactivity from the inescapable shock situation to the testing situation. There was no shock or any stimulus similar to shock present in the dominance testing situation, and any inactivity acquired during inescapable shock exposure should not have been transferred. These incompatible motor response hypotheses could perhaps be modified so that inactivity later occurred without the presence of shock, but it is not evident why this should happen when another rat is present (Experiments 1 and 2) but not when another rat is absent (Experiment 3). Perhaps this problem could be circumvented by postulating fear or arousal as a mediator. However, the fear or arousal produced in the dominance test is prob. ably much less than that produced by inescapable shock. What must be assumed is that weak fear or arousal produces transfer of a motor response learned in a very different situation under strong fear or arousal. This explanation might be capable of accounting for the present results, but it requires a number of assumptions for which there is little, if any, supporting evidence.

Maier, Seligman, and Solomon (1969) and Seligman, Maier, and Solomon (1971) have proposed a learned helplessness explanation of the effects of inescapable shock. They argued that organisms exposed to inescapable shock learn that responding and shock termination are independent and that this learning reduces the organism's incentive to escape shock and interferes with the organism's propensity to perceive subsequent relationships between its own responding and shock termination. Clearly, this mechanism does not predict the present results. Maier and Seligman (1976) and Seligman (1975) have noted that exposure to uncontrollable aversive events also seems to produce an emotional depression and passivity. An emotional deficit or passivity might indeed produce a disruption of dominance. However, neither Maier and Seligman (1976) nor Seligman (1975) provided a mechanism by which inescapable shock produces an emotional deficit, and so such a factor should not be considered an explanation. In addition, strong evidence for the occurrence of such a deficit was not presented. These authors need to detail how an emotional deficit and passivity might be produced and how such a deficit might affect behavior. In addition, in order to account for the present results, any such passivity must be limited to certain emotional or moti- 
vational situations, since an effect only occurred in the presence of another rat. So it must be a reactive passivity, not just freezing or movement reduction.

It might seem that the learned helplessness hypoth. esis would expect the initial dominance test to immunize the rats against the dominance-reducing effects of later inescapable shock exposure. Seligman and Maier (1967) and Williams and Maier (1977) have found that an initial exposure to escapable shock reduces the interference with later escape performance produced by inescapable shock. Perhaps initial dominance testing should have the same effect. However, it should be noted that the immunization effect does not have to be complete. In fact, Williams and Maier (1977) found that prior escape training reduced but did not entirely eliminate the effects of inescapable shock. It is possible that the initial dominance test used here did produce a partial reduction in the dominance-reducing effect of inescapable shock. The effect might have been even larger had an initial test not been employed. The initial test was used so that changes in dominance could be measured. It is not possible to know whether immunization occurred or not without groups which did not receive the initial test. In any case, the learned help. lessness hypothesis explains immunization as resulting from the learning that shock can be controlled. The initial dominance test should not lead to such learning, and so it is not even clear that the learned helplessness hypothesis would here predict an immunization effect.

The present results should only be considered supportive of the learned helplessness hypothesis to the degree that this position expects a wide ranging effect of inescapable shock on behavior, whereas the alternative positions predict more restricted effects. Thus, since none of the existing theories of inescapable shock effects can gracefully account for the findings reported here, these data may stimulate theory toward the direction of explaining how the inescapability of shock can produce deficits in a situation in which no learning or aversive stimuli are involved in any obvious way. Perhaps these data should be taken as a suggestion that uncontrollable aversive events do produce an emotional deficit or passivity.

\section{REFERENCES}

Altenor, A., Kay, E., \& Richter, M. The generality of learned helplessness in the rat. Leaming and Motivation, 1977, 8. 54-62.

Anisman, H., \& W Wller, T. G. Effects of inescapable shock on subsequent avoidance performance: Role of response repertoire changes. Behavioral Biology, 1973, 80, 286-303.

BAENNINGER, L. P. Social dominance orders in the rat: "Spontaneous," food, and water competition. Journal of Comparative and Physiological Psychology, 1970, 71, 202-209.

Bracewell, R. J., \& Black, A. H. The effects of restraint and noncontingent pre-shock on subsequent escape learning in the rat. Learning and Motivation, 1974, 5, 53-69.

CRook, J. H. Social organization and the environment: Aspects of contemporary social ethology. Animal Behaviour, 1970, 18, 197-209.
Drews, D. R., \& Dickey, C. L. Observational and competitive measures of dominance in rats. Psychological Record, 1977, 27, 331-338.

DREWS, D. R., \& WulCzYN, F. H. Measuring dominance in rats. Psychological Record, 1975, 25, 573-581.

Gartlan, J. S. Structure and function in primate society Folia Primatologica, 1968, 8, 89-120.

Glazer, H. I., \& Weiss, J. M. Long-term and transitory interference effects. Journal of Experimental Psychology: Animal Behavior Processes, 1976, 2, 191-201. (a)

Glazer. H. I., \& Weiss, J. M. Long-term interference effect: An alternative to "learned helplessness." Journal of Experimental Psychology: Animal Behavior Processes, 1976, 2. 202-213. (b)

Lindzey, G., Manosevitz, M., \& Winston, H. Social dominance in the mouse. Psychonomic Science, 1966, 5, 451-452.

Maier, S. F., Albin, R. W.. \& Testa, T. J. Failure to learn to escape in rats previously exposed to inescapable shock depends on nature of escape response. Joumal of Comparative and Physiological Psychology, 1973, 85, 581-592.

Maier, S. F., Anderson, C., \& Lieberman, D. A. Influences of control of shock on subsequent shock-elicited aggression. Journal of Comparative and Physiological Psychology, 1972, 81, 94.100.

Maier, S. F., \& Seligman, M. E. P. Learned helplessness: Theory and evidence. Journal of Experimental Psychology: General. 1976, 105, 3-46.

Maier, S. F., Seligman, M. E. P., \& Solomon, R. L. Pavlovian fear conditioning and learned helplessness. In B. A Campbell \& R. M. Church (Eds.), Punishment. New York: Appleton-Century-Crofts, 1969.

Rosellini, R., \& Seligman, M. E. P. Learned helplessness and escape from frustration. Joumal of Experimental Pschology: Animal Behavior Processes, 1975, 1, 149-158.

Ruskin, R. S., \& Corman, C. D. A multivatiate study of competition in a free-operant situation. Psychonomic Science, 1971, 23. 251-252.

Seligman, M. E. P. Helplessness. On depression, development and death. San Francisco: Freeman, 1975.

Seligman, M. E. P., \& Maier, S. F. Failure to escape traumatic shock. Joumal of Experimental Psychology, 1967, 74, 1-9.

Seligman, M. E. P., Majer, S. F., \& Solomon, R. L. Unpredictable and uncontrollable aversive events. In F. R. Brush (Ed.), Aversive conditioning and learning. New York: Academic Press, 1971.

Stewart, J., \& Palfal, T. Castration, androgens, and dominance status in the rat. Psychonomic Science, 1967, 7, 1-2.

VAN KREVLAND, D. A selective review of dominance-subordination relations in animals. Genetic Psychology Monographs, 1970, 81, 143-173.

WEISs, J. M. Effects of coping responses on stress. Journal of Comparative and Physiological Psychology, 1968, 65, 251-260.

Weiss, J. M., Glazer, H. I., \& Pohorecky, L. A. Coping behavior and neurochemical changes: An alternative explanation for the original "learned helplessness" experiments. In Relevance of the psychopathological animal model to the human. New York: Plenum Press, 1975.

Williams, J. L., \& MaIER, S. F. Transituational immunization and therapy of learned helplessness in the rat. Journal of Experimental Psychology: Animal Behavior Processes, 1977, 3, 240-253.

\section{NOTE}

1. One member of Group R became ill on Day 8 and was discarded before any tests were made. All first test results were recomputed without this animal.

(Received for publication June 24, 1977; accepted October 4,1977 .) 